\title{
Dialéticas da ginga: performances dos corpos subalternos em movimento
}

\author{
Ricardo César Carvalho Nascimento \\ Professor Doutor na Universidade da Integração Internacional \\ e da Lusofonia Afro-brasileira, Fortaleza, Ceará, Brasil \\ ricardonascimento@unilab.edu.br
}

Resumo Este artigo tem por finalidade problematizar o conceito nativo de ginga, oriundo da prática da capoeira, tendo como base a situação social vivida no processo eleitoral brasileiro de 2018 com o assassinato do Mestre Moa do Katendê. Esta pesquisa tenta demonstrar que a ginga se constitui como um dispositivo estético e simbólico, que faz parte do repertório performático dos praticantes de capoeira, e pode ser compreendida enquanto artefato de navegação e ação social dos capoeiristas no contexto da sua subalternidade. Trata-se de um estudo de caso em que parti do acompanhamento do assassinato do Mestre, no contexto eleitoral, mas também da conjugação das inquietações acadêmicas e políticas que concernem às vivências de um pesquisador-praticante de capoeira.

Palavras-chave: Performance. Ginga. Capoeira. Discursos ocultos

\section{Introdução}

homenagem a MeSTRE MOA Do KaTENdê

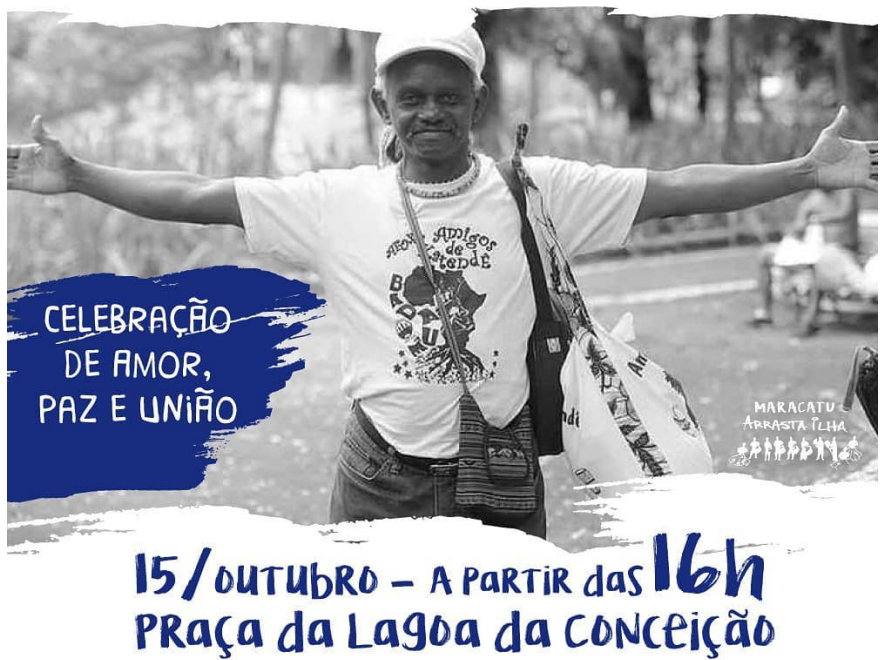

Figura 1 - Roda em Homenagem ao Mestre Moa na cidade de Florianópolis. Fonte: Cartaz público das redes sociais 
No dia 8 de outubro de 2018, Romualdo Rosário da Costa, baiano, 63 anos de idade, conhecido no meio da capoeiragem como Mestre Moa do Katendê, foi assassinado na cidade de Salvador, com 12 facadas, por causa de um desentendimento político com um opositor ideológico, no contexto do fim do primeiro turno das eleições presidenciais brasileiras daquele ano. Ao declarar seu voto no candidato petista ${ }^{1}$, Romualdo entrou em desacordo com um opositor que se encontrava no local e que, ao se retirar da cena de litígio, retornou armado, esfaqueando o mestre de capoeira. $\mathrm{O}$ fato ocasionou uma profunda consternação na sociedade brasileira, aqueceu o debate sobre o momento político-eleitoral, sobre o crescimento do fascismo, do racismo e da intolerância diante do embate político travado naquele período. Um impacto maior foi sentido na comunidade nacional e internacional de praticantes de capoeira que, em várias partes do Brasil e do mundo, manifestaram condolências àquele que, em conjunto com Marielle Franco ${ }^{2}$, se tornou um mártir do enfrentamento ao fascismo no Brasil. Neste artigo, pretendemos render a nossa homenagem ao mestre e, a partir dos fatos que o vitimaram, tencionamos problematizar a ginga, um dispositivo ético e estético dos (as) capoeiristas que é utilizado enquanto instrumento de navegação social dentro e fora da roda de capoeira. No âmbito deste artigo, a ginga deve ser compreendida como um elo que permite analisar como vidas subalternas produzem as suas existências sociais, discursos e recursos de embate social numa sociedade que as rejeita e invisibiliza. $\mathrm{O}$ artigo pretende ainda expor inquietações vividas no campo de estudos que concernem à pertença política e cultural do pesquisador enquanto praticante de capoeira, que dizem respeito às dificuldades de produzir uma análise social que ignore uma interpretação crítica dos fatos políticos e a possibilidade ensaística de relacioná-los aos elementos estéticos como a ginga.

Do ponto de vista metodológico, no âmbito deste estudo de caso, foram utilizadas várias fontes que permitiram reconstruir um breve enxerto da biografia do mestre. Entre essas fontes estão as entrevistas feitas com Moa do Katendê, informações recolhidas nas redes sociais, cartazes que circularam nos espaços virtuais, informações dos noticiários, dossiês acadêmicos sobre a capoeira ${ }^{3}$, observação e acompanhamento das manifestações públicas de homenagem e passagens do filme $A$ primeira vítima ${ }^{4}$, dirigido por Carlos Pronzato, que narram partes da vida e o momento do falecimento do mestre.

A questão que nos inquieta pode ser formulada da seguinte forma: qual a pertinência e relevância atual de dispositivos estéticos, que fazem parte do repertório coreográfico

1 Fernando Haddad o candidato petista disputou o segundo turno com Jair Bolsonaro, o candidato vencedor das eleições presidenciais de 2018.

2 Vereadora negra do Rio do Janeiro assassinada por motivos políticos em 14 de março de 2018.

3 O dossiê temático, Capoeira, Patrimônio e políticas públicas, produzido pela Revista Capoeira (Revista de Humanidades e Letras da UNILAB), que faz uma homenagem de abertura ao Mestre Moa do Katendê.

4 O filme possui 46 minutos, foi produzido com imagens de arquivo, entrevistas recentes e acompanhamento dos atos de homenagens ao Mestre. Por razões políticas e de divulgação, o filme foi disponibilizado no canal youtube: https://www.youtube.com/watch?v=-iV7RQ_oc5U 
das populações afro-brasileiras, no domínio das vivências e enfrentamentos sociais das desigualdades das populações subalternizadas no Brasil? De um ponto de vista teórico, no que concerne o entendimento da ginga, fazemos uso das premissas de James Scott (2013), que defende que existe um conjunto ou repertório de disfarces, estratagemas e ardis que fazem parte do que ele denomina de discurso oculto e público dos dominados. Todos os grupos subalternizados criam, a partir da sua experiência de sofrimento, um discurso oculto que representa uma crítica ao poder, expressa nas costas dos dominadores. O autor chama a atenção para o fato de que os discursos ocultos não tomam apenas a forma verbal, mas um conjunto vasto de possibilidades que envolvem sempre a dissimulação, o disfarce e que abarcam toda a cultura popular subalterna (SCOTT, 2013, p. 19).

\section{Mestre Moa, gingando com a vida e esquivando da morte}

Romualdo Rosário da Costa, conhecido como Mestre Moa do Katendê, nasceu em Salvador em 29 de outubro de 1954, oriundo de uma comunidade simples e periférica. Nascido em uma família religiosa, ligada ao Candomblé, é no terreiro familiar de sua Tia, na casa Ilê Axé Omim Bain, que iniciou sua relação com a cultura afro-baiana, e onde se tornou Ogam Alabê $\hat{e}^{5}$. Ao nos reportarmos à sua vivência religiosa nas religiões de matriz africana no Brasil, não nos centramos apenas no domínio vivencial da espiritualidade afrodiaspórica, mas a uma série de práticas culturais que envolvem a construção do ethos religioso afro, como a cultura gastronômica, o vestuário, a música, a dança e o canto dos terreiros. Portanto, falamos de um vasto campo epistemológico de saberes apreendidos nos processos de incorporação, vivência e constituição de um habitus próprio. A construção do seu nome artístico, pelo qual ficou conhecido em todo mundo, fez-se pela adoção do apelido Moa, adquirido na infância, e do vocábulo Katendế ${ }^{6}$, tendo sido este último agregado, por força da sua participação na adolescência, em um grupo folclórico escolar que carregava o mesmo nome.

A trajetória de Moa do Katendê na capoeira, que teve início aos oito anos de idade, deu-se a partir da participação nas aulas do Mestre Bobó, que morava próximo de sua casa. Para além dos seus dotes de exímio capoeirista, o mestre também era percussionista, artesão, alfaiate, dançarino e compositor, tendo tido um papel relevante no cenário musical afro-baiano. Em 1977, Moa venceu o festival Ilê Aiyê, um importante bloco afro carnavalesco da Bahia. Em 1978, fundou e levou para a avenida o afoxé Badauê, com ele foi galardoado com prêmios. As suas composições chamaram a atenção da elite musical baiana e alguns dos renomados compositores brasileiros, caso de Caetano Veloso e Gilberto Gil, gravaram algumas das suas músicas. De acordo com Risério (1981), Moa era um inovador de tal ordem que, na criação do afoxé Badauê, Gilberto Gil os batizaria

5 Cargo religioso masculino e de extrema importância no terreiro. Sujeito responsável por comandar o ritual tocando os atabaques e conduzindo os cânticos litúrgicos.

6 Inkissi Katendê é uma divindade masculina das mais importantes do Candomblé Angola, associada às matas, folhas, aos encantamentos e plantas medicinais. 
de um "afoxé pop", dadas as inovações musicais, a indumentária e a dança. O Bairro do Engelho Velho de Brotas, em Salvador, onde nasceu o Badauê e onde Moa do Katendê fez o seu percurso, é conhecido por ser um bairro essencialmente formado por uma população negra, historicamente um antigo engenho onde trabalharam escravizados, mas também um celeiro da cultura afro-baiana com inúmeros terreiros e afoxés.

Algumas semanas antes dele ser assassinado, tivemos a oportunidade de entrevistálo, ouvir as suas músicas e percebermos, por seus depoimentos, aspectos da sua vida e aprendizagens:

Eu comecei a capoeira na década de 60 e meu mestre já tinha uma didática. Eu me lembro como eu aprendi a ginga. Então, o mestre fez um risco no chão. Ele dizia, coloca a perna esquerda aqui, o braço direito e vai trocando, depois você pra lá e pra cá. E fazia todos os pontos pra gente entender que a ginga não era só prum lado, você tem que ter um foco. Se a pessoa for pro lado de lá você acompanha. Ele fazia um risco, como se fosse uma cruz pra você entender que a capoeira tem sinais. A ginga está presente em tudo, ela é a expressão do corpo. É a conexão do corpo com a musicalidade, com o tempo da música. Pode ser na dança afro, pode ser no samba, pode ser no maculelê, pode ser na puxada de rede, ele está presente em tudo. No próprio futebol. O futebol tem essa ginga, a ginga brasileira da capoeira mesmo, ela está dentro do futebol. Essa ginga que foi exportada mesmo, a gente vê que os europeus aprenderam essa ginga, esse nó de corpo que tem na capoeira. (Depoimento do Mestre Moa do Katendê, 9 de setembro de 2018)

Compreendemos, a partir de apontamentos da sua vida que nos foi dado em depoimento, que Moa era um homem negro marcado por sua própria cultura e dela fez uso sempre como meio de sobrevivência e afirmação identitária. Segundo nos disse o mestre, a ginga é o grande segredo da cultura afrodiaspórica, estando presente em várias práticas culturais de matrizes africanas. Enquanto dispositivo estético, mas que enseja mecanismos de navegação social, a ginga foi na verdade o artefato que permitiu ao mestre, como homem negro, periférico e vítima de preconceito racial, manter-se vivo. Com efeito, a ginga foi seu ganha-pão e seu instrumento de desenrasque social.

Acompanhamos, na cidade de Fortaleza, o conjunto de quatro manifestações feitas por capoeiristas locais por ocasião da morte do mestre, que se inseriram enquanto manifesto de reprovação política ao clima de intolerância e fascismo que se instaurou na ocasião. As manifestações ocorreram em locais públicos, agregando militantes dos movimentos sociais, artistas locais e muitos praticantes de capoeira. Entre os diversos atos políticos que ocorreram no Brasil e no mundo, destacamos o movimento realizado no bairro do Pelourinho, no centro histórico da cidade de Salvador, onde capoeiristas, intelectuais, artistas, militantes, familiares e acadêmicos prestaram homenagem ao mestre. Meses após a sua morte continuam ainda a serem feitas menções honrosas ao mestre em rodas, encontros, nomes de rua, estampas de camisas, cartazes, slogans dos movimentos sociais e tudo mais quanto possa manter seu legado. Não foi dificil perceber, à semelhança de outras tantas partes do Brasil, que nem toda comunidade de capoeiristas esteve presente 
e que havia uma divisão marcada que acabou por opor lideranças dos mesmos grupos de capoeira. Muitos líderes locais de grupos de praticantes apressaram-se por condenar as manifestações, enfatizando que a capoeira é apenas uma prática esportiva e, como tal, manifestações de ordem política não seriam bem-vindas.

A partir do assassinato do saudoso mestre foram retomados os debates entre os capoeiristas sobre a relevância e o valor histórico da capoeira enquanto luta social e seu papel militante diante das escolhas postas nas encruzilhadas políticas da sociedade brasileira. Deste modo, no contexto da morte de Moa, a comunidade de praticantes sentiu a necessidade de realizar uma reflexão coletiva sobre o sentido libertário atribuído à capoeira e sobre o engajamento dos sujeitos capoeiristas nas lutas sociais. Diante do trágico assassinato de um líder negro, fazia-se necessário resgatar pertenças históricas e continuidades da luta social que sempre fizeram parte das narrativas de formação da capoeira.

\section{(In) Definições da ginga}

De acordo com Rosa (2010), a ginga deve ser entendida no seu formato estético, como uma forma de síncope corporal, que parte da articulação de pernas e ancas para todo o corpo, mas que é central enquanto patrimônio cultural afro-brasileiro. É importante referir que, nesse formato, a ginga pode ser encontrada em várias outras práticas, tal como no samba e nas religiões de matrizes africanas no Brasil.

Rosa (2010) nos explica que a estética da ginga tem a capacidade de disciplinar os corpos e, a partir deles, produzir conhecimentos não hegemônicos e visões do mundo que se contrapõem ao pensamento ocidentalizante. Neste domínio, podemos refletir, com base na ginga, sobre o atravessamento que compreende os corpos, suas estéticas, o movimento e a produção de pensamento social e político nas suas formas de ação na sociedade.

Muitos capoeiristas acreditam que o vocábulo ginga seja uma derivação, ou corruptela, do nome da rainha africana NzingaMbandiNgola. Segundo Glasgow (2003), trata-se de uma personagem importante da história africana, que viveu entre 1581 a 1663, no que é hoje o território angolano, e que liderou a resistência africana contra o colonialismo português e o tráfico de escravizados. Embora seja possível traçar uma conjetura sobre a origem do nome ginga, sua definição é bem mais complexa. Waldeloir Rego (1968), no seu clássico livro Ensaio etnográfico da capoeira Angola, destaca algo que parece ser um consenso alargado entre praticantes e pesquisadores, a importância e centralidade da ginga no jogo da capoeira:

O jogo da capoeira é algo dificil, complicado e requer uma atenção extraordinária, senão poderá ser fatal para um dos jogadores. $\mathrm{O}$ capoeira tem que ser o mais possível leve, ter grande flexibilidade no corpo e gingar o tempo todo durante o jogo. A ginga é elemento fundamental. Da ginga é que saem os golpes de defesa e ataque, não só golpes comuns a todos os capoeiras, como os pessoais e os improvisados na hora. (REGO, 1968, p. 57) 
Note-se que Rego em seu comentário destaca dois elementos exegéticos da ginga, a concentração e a flexibilidade. Podemos compreender a concentração como uma espécie de uso condensado dos sentidos, que nela se tornam unos. Deste modo, o desenvolvimento refinado e o uso agregado das formas sensoriais de percepção põem a ginga no lócus do jogo da capoeira. Sua segunda característica, a flexibilidade, implica não apenas a capacidade fisica de se contorcer e se moldar ao jogo, mas também de refazer os sentidos atribuídos à ginga, que é ressignificada a cada momento em que o jogador entra em cena, não apenas na roda de capoeira, mas também nos diferentes espaços sociais em que circula.

Entre as tentativas de definir a ginga, destacamos a definição da pesquisadora e mestra de capoeira Janja Araújo (2004), dada como nota de rodapé em sua tese de doutorado:

Ginga: movimento fundamental, do qual partem todos os golpes ofensivos ou defensivos, e em que o capoeirista, agitando-se sem deixar de manter a base de apoio, em conjugação com as mãos, procura iludir e desnortear o adversário. Molejo, malandragem, astúcia, "jogo de cintura”, dissimulação etc., atributos de conduta que podem ser valorizados simultaneamente como sendo positivos e negativos. Indica a capacidade de negociar determinadas situações, aprendendo a reconhecer os momentos de recuo como condição de se manter jogando. Também se refere à Rainha Ginga, entidade da nobreza religiosa nas festividades do congado, espalhadas pelo Brasil. (ARAÚJO, 2004, p. 26)

A ideia de dissimulação, ocultar intenções, distrair e disfarçar, são algumas das conceituações que atravessam o conceito da ginga, como assevera o renomado Mestre Pastinha em sua definição:

A palavra "ginga", em capoeira, significa a perfeita coordenação de movimentos do corpo que o capoeirista executa com o objetivo de distrair a atenção do adversário para torná-lo vulnerável à aplicação dos seus golpes. Os movimentos da ginga são suaves e de grande flexibilidade - confundem facilmente a quem não esteja familiarizado com a capoeira, tornando-o presa fácil a um agressor que conheça essa modalidade de luta. $\mathrm{Na}$ ginga se encontra a extraordinária malícia da capoeira, além de ser uma característica fundamental. (PASTINHA, 1988, p. 40).

Na definição dada por Tavares (2013), o autor se refere à ginga enquanto uma pauta que se insere na cotidianidade dos capoeiristas em seu modo constante de jogo e alerta.A essa pauta se junta a capacidade interpretativa do jogo, através do corpo, que é dada pela própria ação da ginga:

A ginga, portanto, é pauta por onde se configuram os arranjos cinéticos das defesas e dos ataques. É ela um elemento essencial para a execução da prática, atuando por um efeito dissimulador da intenção. A leitura desta intenção será feita pelo jogador, por intermédio da percepção da linguagem corporal adotada pelo adversário. A esta se chega por um olhar fixo nos olhos do oponente-parceiro. (TAVARES, 2013, p. 100) 
Em geral, acredita-se que a ginga é a natureza principal do capoeirista, sua identidade e constituição essencial. Mestre Decânio $(1997)^{7}$, um dos mais importantes pensadores da Capoeira Regional, descreve a ginga como:

Um movimento de balanço em vaivém de todo o corpo, ritmado, acompanhando a cadência do berimbau. Nasce da cintura e se propaga para o tronco, membros e cabeça. (DECÂNIO, 1997, p. 240).

A ginga, de fato, não é movimento de fácil descrição textual, contudo percebese que a força motriz de sua eficácia, como nos dizem os depoimentos, é o fato de que este dispositivo é capaz de mobilizar partes distintas do corpo, reunindo energias que conferem destreza e habilidades camaleônicas aos praticantes. Adiante em seus escritos, Mestre Decânio nos indica também que "o movimento original é o gingado. Movimento fundamental, raiz donde se derivam os demais componentes da capoeira" (DECÂNIO, 1997, p. 225). Observe-se que o mestre faz uso da palavra em sentido de ação, gingado. É importante referir, nesta passagem, que a ginga aqui aparece como uma técnica central de onde saem os demais movimentos, que também se agregam e podem ser considerados expansivos da própria ginga. Acerca de como se deve desenrolar a ginga em sua aprendizagem e uso, Mestre Decânio define os seguintes parâmetros:

O gingado praticado lentamente durante cerca de três minutos, mentalizando cada movimento e executando todos que dele podem ser iniciados, funciona como método de aquecimento, relaxamento mental e alongamento muscular. Convém acentuar que o gingado deve ser praticado deslizando os pés no chão, suave e delicadamente, com o corpo pronto para flutuar em movimento de esquiva ou partir para um ataque, sempre apoiado no chão durante os movimentos de balanceio. $\mathrm{O}$ tronco deverá pender levemente para diante facilitando os movimentos de esquiva para trás, para os lados e para baixo e a inclinação do tronco para traz, pelo desequilíbrio que acarreta e torna os movimentos mais lentos. (DECÂNIO, 1997, p. 200)

Bola Sete (2005), em seu livro, nos apresenta uma longa descrição da forma como se deve executar a ginga e chama a atenção para a necessidade da precisão dos movimentos, tendo em conta a importância da ginga no jogo:

É o principal movimento da capoeira. Na ginga, o capoeirista poderá defender-se com o auxílio das mãos e dos braços, negociando em várias posições, deslocar-se para qualquer direção, permitindo-lhe uma melhor posição para defesa. $\mathrm{O}$ ataque e o contra-ataque, além da utilização do "floreio", que consiste no jogo de corpo, no qual o capoeirista, como o nome já diz, utiliza movimentos corporais, com o intuito de distrair o adversário para melhor aplicar-lhe o golpe. Sendo a ginga o principal movimento da capoeira, devemos procurar aprendê-la com o máximo de perfeição possível. (BOLA SETE, 2005, p. 50)

7 Mestre Acordeom e Decânio foram antigos alunos do renomado Mestre Bimba, criador da capoeira Regional. 
De acordo com Lewis (1992), "ginga" é um nome técnico da capoeira, mas que pode ser encontrado na língua portuguesa em diversos sentidos, próximos aos atribuídos na capoeira. $\mathrm{O}$ autor enfatiza que as formas de ensino da ginga variam da capoeira Angola para a Regional, sendo esta última mais rígida no seu formato. Alguns mestres diferenciam cerca de três grupos de movimento, a defesa, o ataque e a ginga. Enquanto os dois primeiros aparecem como pacotes de movimentos, a ginga se encontra isolada, dada a sua importância. Contudo, o autor observa que todos os movimentos, incluso o da ginga, podem funcionar em simultâneo como ataques, defesas, fazendo parte integrada da ginga. A ginga pode ser ataque ou defesa, ou nenhum deles. Lewis percebe que, num nível avançado, os jogadores se entranham em um emaranhado em que não se percebe com precisão o que se entende por defesa ou ataque. Tudo pode ser ataque ou defesa ao mesmo tempo, sendo esse um dos sentidos amplos da ginga.

Em sua etnografia, o antropólogo Greg Downey (2005) indica que, no entendimento dos seus informantes, a ginga é o fundamento da malandragem da capoeira. A ginga envolve um completo comprometimento do corpo que se inicia na cintura. As suas observações levaram a refletir que, na capoeira, existe uma peculiar incidência do corpo sobre o tronco, em particular no movimento gesticular da ginga, o que contrasta com as outras artes marciais. Downey enfatiza que em muitas formas de luta e dança os neófitos são levados a desenvolver um senso de entendimento do centro de gravidade do corpo, que em geral pode localizar-se abaixo do umbigo. $\mathrm{O}$ autor explica que, nessas disciplinas corporais, o tronco é representado como uma raiz estável de fonte energética e um princípio postural de firmeza. No entanto, na capoeira, o tronco, a cintura e a coluna devem permanecer flexíveis e propulsoras de evoluções de todo o corpo. Essas experimentações de flexibilidade estruturante do corpo permitem ao praticante vivenciar, também, posturas corporais extras cotidianas, que ampliam possibilidades de compreensão da gramática corporal.

No entanto, para muitos pesquisadores-capoeiristas, enquanto categoria particular de sujeitos praticantes e acadêmicos, é impossível não realizar uma reflexão mais ampla que permita compreender a ação social e cosmológica da ginga no domínio da vida em sociedade, mas também nos sujeitos que se deixam afetar por este formato étnicoestético da herança cultural africana na diáspora. É deste modo que Janja Araújo (2003, p. 22), mestra angoleira ${ }^{8}$ e pesquisadora, teoriza: “[...] numa Roda de angoleiros devemos estar certos de que descobriremos neste jogo que gingar, mais que uma atitude corporal, configura uma filosofia de vida”.

Ademais, há o entendimento de que a ginga ultrapassa os limites de seu aprendizado em uma classe de capoeira, servindo como metáfora para o mundo social e para o universo simbólico de seus atores:

Aqui tomando o termo gingar não apenas como o movimento primário da capoeira, de onde partem todos os outros, mas também como o exercício de 
um jogo que impõem conteúdos verbalizados distintamente na pluralidade de suas origens e procedências. (ARAÚJO, 2003, p. 26)

Cristina Rosa (2010), em sua tese, entende a ginga como um tipo particular de forma corporal sincopada, central na herança cultural afro-brasileira. Rosa acentua que a ginga, no seu espectro mais vasto, envolve saberes não hegemônicos cultivados e transmitidos na diáspora através de discursos não verbais que reimaginam a África no Brasil. A autora confere à ginga um estatuto epistemológico de produção e transmissão de visões do mundo, modos de estar e ser em sociedade que partem de um disciplinamento estético dos corpos a partir da prática da capoeira e em contraponto ao pensamento eurocêntrico. Em seu trabalho de pesquisa, a autora perscrutou a ginga em vários domínios, encontrandoos na capoeira, no samba e nas artes performáticas.

De todo modo, neste trabalho concebemos a ginga como uma linguagem conceitual que ultrapassa, no domínio estético, a ginga da capoeira e se encontra em muitas outras práticas africanas da diáspora. Enquanto metalinguagem, a ginga compreende uma forma de ver e agir sobre o mundo a partir da gramática interpretativa da cultura afro-diaspórica.

\section{Dialéticas da ginga}

Segundo Cristina Rosa (2010), a dialética da ginga pode ser compreendida como um sistema de organização corporal que implica na produção de conhecimento. A pesquisadora enuncia que o jogo de cintura, de onde deriva o movimento da ginga, é um dispositivo que resulta de uma experiência corporal e que se expressa através do vocabulário de um movimento, mas, acima de tudo, é uma reposta fisica e social que resulta das relações assimétricas de poder. Através da prática da ginga, em sua dialética, praticantes conseguem, segundo a autora, traduzir suas ideias em linguagens simbólicas. O conceito de dialética da ginga nos permite perceber que, mais que um conjunto articulado de movimentos, a ginga pressupõe a compreensão da ação do corpo físico enquanto corpo social e as coreografias como formas de conhecimento, ação social e afrontamento político.

Muitos autores ao longo do tempo têm se debruçado sobre o tema das estéticas africanas na diáspora a partir das suas performances, que envolvem o corpo, a dança e a música. A ginga é um desses dispositivos corporais e simbólicos que, tendo sido desenvolvidos pelos africanos da diáspora, foram gestados não apenas como instrumentos das práticas culturais, mas também das performances da vida cotidiana, inscrevendo no corpo comportamentos sociais duradouros.

Devemos pensar que as problematizações acerca da estética africana e afro-diaspórica não estão desprovidas de um debate social e político da representatividade dessas culturas na atualidade. Falar de estética, neste âmbito, é pensar identidades culturais, processos de resistência e formas de luta. Elas nos fornecem excelentes pistas sobre os processos culturais, como operam os seus mecanismos, dispositivos e subjetividades. 
Paul Gilroy (2001), em O Atlântico Negro, lança bases para pensarmos as culturas negras da diáspora. O Atlântico Negro foi imaginado por Gilroy (2001) não apenas como um espaço geográfico onde decorrem os processos da escravidão africana, mas também como espaço de expressão cultural desta diáspora, nas suas mais diferentes morfologias:

Formas culturais estereofônicas, bilingues ou bifocais, originadas pelos - mas não propriedade exclusiva dos - negros dispersos nas estruturas de sentimento, produção, comunicação e memória, a que tenho chamado heuristicamente, mundo atlântico negro. (GILROY, 2001, p. 35)

Uma das primeiras aprendizagens de um neófito na prática da capoeira é a ginga, possivelmente a mais importante produção estética da diáspora africana no mundo, hoje produto de exportação (NASCIMENTO, 2015). Muito embora a aprendizagem da ginga seja parte intrínseca da cotidianidade de um praticante de capoeira, é certo que, por todo seu percurso, a ginga será trabalhada e retrabalhada. A ginga é a forma como o capoeirista inventa e reinventa sua própria identidade na capoeira. A aprendizagem da ginga pode ser longa, mesmo que, aparentemente, um novo praticante possa achar que a apreendeu logo nas suas primeiras vivências.

Para os mais antigos nesta arte, revisitar a ginga é constante e, ao fim de um tempo, fazê-lo é buscar um entendimento muito pessoal de sua própria persona, do seu íntimo e de sua pertença na arte da malandragem capoeirística. Entendida como a base da capoeira, a ginga é uma reinvenção do ato fisico de caminhar. Ginga-se como se caminha. No entanto, essa reinvenção do movimento físico de caminhar não é despropositada, uma vez que o ato de caminhar enquanto forma de movimento corporal se normatizou e foi formatada por estruturas rígidas, como as de caminhar numa passarela ou a marcha militar.

No jogo da capoeira a ginga é o movimento catalisador de todos os outros, incluso os da esquiva e do ataque. Ambos se integram à ginga, formando o seu corpo mais vasto e dilatado. É importante ressaltar que o gestual da capoeira se aproxima dos movimentos utilizados na vida cotidiana e dela fazem parte. A título de exemplo, apresentamos uma das esquivas mais expressivas encontradas em todos os segmentos da capoeira, a "cocorinha". Trata-se de um movimento em que o praticante agacha e, de cócoras, defende-se do golpe, à medida que amplia seu campo de visão de baixo para cima. A "cocorinha" nada mais é do que o gesto físico de defecar, um ato fisiológico da vida humana agora restaurado na capoeira com outra função.

Nas nossas sociedades, o ato de caminhar corretamente pressupõe uma postura física ereta, um corpo firme, postural e normativo. De um ponto de vista da ética religiosa cristã, caminhar é percorrer percursos de retidão, assertividade social e espiritual de um bom comportamento religioso. A ginga, por sua vez, subverteu essas lógicas do caminhar, pensando outras formas de transferência do peso corporal em que o importante não é o equilíbrio, e sim o desequilíbrio. Em sua dialética, não é possível compreender com precisão o que é a ginga e os domínios da sua expressão. Sua magnitude epistemológica é ampla, como nos indica a Mestra Janja Araújo quando nos diz: 
A ginga é uma palavra polissêmica, e também, poli lógica. Ela tem em si os seus próprios contrários. (Depoimento da Mestra Janja Araújo, setembro de 2018)

Muito embora a ginga tenha sido adestrada por alguns segmentos e, em alguns casos, esses segmentos e seus mestres representativos tenham se tornado o modelo de difusão e formato da ginga, muitos mestres creem que a ginga se desenvolve, que se encontra na pessoa, bastando apenas estimular o seu desenvolvimento. Romualdo Rosário da Costa nos empresta a sua visão particular sobre a ginga:

A ginga é a própria dança da capoeira. É aonde a gente monta toda uma estratégia de como se posicionar perante a própria roda e perante a sociedade. Como se livrar, como se defender, como proceder num momento de uma dificuldade, se manter calmo, e a ginga ela proporciona várias situações. A ginga pode variar sempre. O ideal é que a gente mostre a base da ginga, mas passe para o aluno que ele busque, dentro dele, a forma dele gingar. A gente não pode padronizar, nós passamos o movimento, mas primeiro ele incorpora, ele interpreta o movimento dele, e a gente não pode mudar. Tem que deixar ele livre para se expressar. A capoeira como um todo trabalha com a coisa da libertação, como superar os medos, como lhe dar com a diversidade, como lhe dar com uma situação até difícil que possa aparecer. A gente tem que ensinar como a capoeira pode servir pra vida das pessoas. (Depoimento do mestre Moa do Katendê, setembro de 2018).

O espaço físico da ginga é multidimensional, pode se gingar para qualquer lado e de qualquer forma. A sua lógica operativa é circunstancial, ginga-se conforme a música, diriam os capoeiristas experimentados. A reflexão lançada por Martins (2015) sobre as danças de origem negro-africana indica que elas possuem um trânsito do corpo que compreende três pilares, sendo um deles o policentrismo. Esse conceito enfatiza que o corpo não possui um ponto fixo de execução dos movimentos, mas desloca-se com alguma liberdade no espaço. Nas danças ocidentais, o corpo está restrito a deslocamentos contíguos, o que não é o caso das culturas afro, que são capazes de realizar deslocamentos inesperados, improvisações, usos abruptos do espaço e dilatações do corpo. $\mathrm{O}$ ato da ginga é o corpo dilatado do capoeira, uma expansão e expressão do próprio self do capoeirista, se não mesmo da sua consciência reflexiva que se faz sentir dentro e fora da roda. A Antropologia Teatral de Eugenio Barba (1999) nos fornece uma compreensão aprimorada do que se pode entender como um corpo dilatado:

O corpo dilatado é acima de tudo um corpo incandescente, no sentido científico do termo: as partículas que compõem o comportamento cotidiano foram excitadas e produzem mais energia, sofreram um incremento de movimento, separaram-se mais, atraem-se e opõem-se com mais força, num espaço mais amplo ou reduzido. (BARBA, 1999, p. 54).

Uma das regras mais importantes do renomado mestre Bimba, criador da capoeira Regional baiana, era gingar sempre. É muito comum que, em uma aula de capoeira, o 
mestre comande a seguinte indicação: vamos trabalhar a ginga? A atribuição de sentidos ligados ao trabalho não se aplica ao que entendemos normalmente no universo laboral, mas sim a ideia de polir, refinar, reeducar, repensar ou refazer. Deste modo, a ginga confere um atributo adicional à identidade do indivíduo, compreendido como um ser incompleto e em constante desequilíbrio. A ginga pressupõe que não estamos prontos, que podemos melhorar e que, ao longo de nossas vidas, algo mais pode ser acrescentado. Assim, a ginga também pode ser pensada como renovação, tendo como base metafórica o caminhar do capoeira na sua aparência gestual.

Para muitos praticantes, a estética pessoal da ginga, na roda de capoeira, é a expressão mais profunda da forma de ser e estar de cada indivíduo. Ou seja, ao gingarmos, revelamos, saímos dos nossos esconderijos e nos despimos das máscaras que utilizamos nas nossas vidas cotidianas. Ao contrário dessa visão, compreendo que o retrabalhar constante da ginga produz muitas outras máscaras, personagens, seres e personas incompletas que se reinventam ao gingar e que representam faces diferentes do mesmo sujeito. Ao partirmos desse pressuposto, a ginga nos mostra que não existe uma forma essencial de ser humano e que esse sentido de humanidade não se reserva a um entendimento simplificado e unitário de si mesmo.

No entanto, aqui queremos referenciar que, embora a ginga possa ser apreendida no seu formato gestual, no processo de aprendizagem da capoeira, ela na verdade é uma ideia, um conceito. Como tenho afirmado, a ginga é uma forma de caminhar, em caminhos tortuosos em que nem sempre se pode e deve ter uma postura ereta e linear. A mestra Janja Araújo nos elucida que o entendimento do que pode ser a ginga encontra sua inteligibilidade através de uma perspectiva mais ampla da sua relação dialógica entre o que chama de pequena e grande roda:

$\mathrm{Eu}$ tenho tentado construir uma interpretação da ginga como uma metalinguagem. Estou querendo me aproximar dessa interpretação da leitura que ela articula em relação às nossas vivências entre a pequena roda e a grande roda. A roda do fazer capoeira, e de estar nela enquanto jogadora de capoeira, e a roda da vida, que a gente chama de a grande roda, é onde de fato a gente, a meu ver, se faz capoeirista. (Depoimento da Mestra Janja Araújo, setembro de 2018)

Ao afirmá-la enquanto metalinguagem, quer se dizer que sua compreensão e alcance estão para além do formato gestual e estético apresentado na capoeira. Devemos compreendê-la, a partir da noção de incorporação e centralidade do corpo, como dispositivo de apreensão e formulação de conhecimento. O saber incorporado pressupõe uma condição existencial em que o corpo é o recurso intersubjetivo da experiência (CSORDAS, 1999). Deste modo, é possível pensar que o processo de aprendizagem da ginga extrapole o microcosmo da pequena roda (roda de capoeira) para a grande roda (sociedade). Com efeito, precisamos compreender que o corpo fisico do capoeira não se dissocia do seu corpo social, nem dos seus processos mentais, de ação, simbolismo e reflexão. 


\section{Considerações finais}

Na manhã de 8 de outubro de 2018 começamos a rever e analisar as entrevistas em vídeo que me foram concedidos por Mestre Moa semanas antes do seu assassinato. Ao tempo em que conduzo esta infindável e inacabada pesquisa sobre a ginga, tive a impressão de que as falas do mestre, de tão boas, teriam completado e esgotado o que se poderia dizer da ginga, dada a precisão das suas palavras sobre o tema. Foi grande o meu espanto ao ver, no momento em que iniciava a execução dos vídeos, a notícia do assassinato do meu principal interlocutor ao vivo na TV. Um choque catártico e contrastante de imagens me tomou de súbito. Entristeci e me confinei por um momento. Nessa breve reclusão me perguntei sobre o que fazer e dizer dessas imagens e como explicar a confluência de situações em que a morte e a vida estavam presentes, no mesmo segundo. Perdido nas encruzilhadas de Exu, me deparei com a dificuldade de expressar e processar explicações sobre os fatos da pesquisa que me interpelavam, aparentemente para além do entendimento do meu objeto de estudo, a ginga. No entanto, a ginga, que também é de Exu como explicou Moa, foi o amparo necessário para compreender que, entre vida e morte, gingar é preciso.

$\mathrm{Na}$ entrevista que me concedeu, o mestre falou das agruras e dificuldades da sua vida enquanto homem negro. Contou-me ainda do ambiente cultural do seu bairro periférico, onde a música, a dança, a capoeira, os afoxés e os terreiros constituíam os únicos espaços de socialização e aprendizagem disponíveis aos indivíduos subalternos. Falou-me sobre a ginga e de como ela estava presente em todos esses territórios formadores do seu ser artístico. Intuí, naquele momento, que o mestre me tratava circunstancialmente como seu discípulo ${ }^{9}$ para explicar que a ginga, este simples trocar de pernas e braços que encontramos nas práticas culturais afro-brasileiras, teria representado para ele, como para muitos outros, uma forma de sobrevivência que extrapolava os limites do seu corpo e o tornaram quem foi, na vida como na morte.

Diante do algoz que o vitimou, o mestre deferiu seus últimos golpes, argumentando veementemente contra o fascismo, justificando seu sentido de voto a partir de sua biografia e condição social. Consta que Paulo Sérgio, o assassino, também ele um homem negro e morador da periferia, recebeu com desagrado as palavras de Moa e resolveu vitimá-lo com 12 facadas.

A escolha desses fatos, a forma de os narrar e a possibilidade de problematizar a ginga a partir deles não foi por acaso. Decerto que a condição de elaboração deste artigo encontra sua transversalidade na indignação política e na homenagem a uma figura importante da nossa história recente. Ademais, também quer lançar inquietações acadêmicas, em confronto com dilemas políticos, sobre como se faz ciência sem desprezar insights, momentos de reflexão retirados do campo e um certo estilo ensaístico que

9 Condição de relação profunda e duradora entre um mestre e seu aluno seguidor na prática da capoeira. 
permite relacionar a pertinência da ginga enquanto dispositivo explicativo da biografia de um líder como Moa do Katendê.

Na perspectiva de James Scott (2013), a ginga pode se constituir como um discurso oculto ou formas dissimuladas de ação social realizadas nas costas dos opressores. Como nos explica o autor, os discursos ocultos são realizados fora da cena e do campo de observação dos detentores do poder e podem ser pensados a partir de gestos, práticas, rituais e performances. Podemos ainda as conceber como formas de insubordinação e infrapolítica dos subalternos. Devemos pensá-los como estratégias, dispositivos e instrumentos de reflexão e ação que permitem compreender a realidade social e agir sobre ela. Os processos de aprendizagem e apropriação desses dispositivos passam pelo corpo, pela interiorização e incorporação de elementos culturais, da partilha de vivências e mecanismos metafóricos, acionados pela aprendizagem corpórea, que possibilita transportá-los para além do espectro formal da roda de capoeira.

A memória de Moa continua viva. Os efeitos sociais de sua morte foram capazes de lançar novos debates sobre o papel da capoeira e a sua pertinência enquanto movimento social. Gingar é preciso, viver também é preciso.

Mestre Moa, presente!

\section{Referências}

ARAÚJO, Rosangela Costa. Iêviva meu mestre: a Capoeira Angola da "escola pastiniana” como práxis educativa. 2003. Tese (Doutorado em Educação) - Universidade Federal da Bahia, Salvador, 2003.

BARBA, Eugenio. $A$ arte secreta do ator. Campinas/SP: UNICAMP, 1999

CSORDAS, T. Embodiment and cultural Phenomenology. In: GAIL, W.; HONI F. H.; Perspective on Embodiment: Intersections of nature and culture. New York: Routledge, 1999, p. 143-164.

DOWNEY, Greg. Learning Capoeira. Oxford: Oxford University Press, 2005.

DECÂNIO, Ângelo Filho. A herança de Mestre Bimba. Coleção São Salomão, Salvador, 1997.

GILROY, Paul. O atlântico negro: modernidade e dupla consciência. São Paulo, Editora 34, 2001.

GLASGOW, Roy. Nzinga. Resistência africana à investida do colonialismo português em Angola, 1582-1663. São Paulo: Perspectiva, 2003.

LEWIS, Lowell. Ring of Liberation: Deceptive discourse in Brazilian capoeira. University of Chicago, Chicago Press, 1992.

MARTINS, Suzana. Corpo em trânsito entre a ação e a divindade: Polirritmia, Policentrismo e Sentido Holístico. Conceição/Conception, Campinas, SP, v. 4, n. 1, p. 22-30, jan./jun. 2015.

NASCIMENTO, Ricardo César Carvalho. Mandinga for export: a globalização da capoeira. 2015. Tese (Doutoramento em Antropologia) - Universidade Nova de Lisboa, Lisboa, 2015.

NASCIMENTO, Ricardo César Carvalho, VARELA, Sérgio González. Abertura do dossiê temático: Capoeira, patrimônio e políticas públicas. Revista de Humanidades e Letras. UNILAB. v. 4, n. 2, 2018.

RISÉRIO, Antônio. Carnaval ijexá; notas sobre afoxés e blocos do novo carnaval afro-baiano. Salvador: Corrupio, 1981.

REGO, Waldeloir. O Ensaio etnográfico da Capoeira Angola. Salvador, Editora Itapoã, 1968. 
ROSA, Cristina. Choreographing Identification the Presence of Ginga in Samba, Capoeira and Grupo Corpo. California, 2010.Tese (Doutorado em Filosofia da cultura e da performance) - Universidade da Califórnia.

SCOTT, James. A dominação e a arte da resistência: discursos ocultos. Lisboa, Letra Livre, 2013.

SETE, Bola. A Capoeira Angola da Bahia. Rio de Janeiro: Pallas, 2005.

TAVARES, Júlio César. Dança de guerra, arquivo e arma: elementos para uma Teoria da Capoeiragem e da Comunicação Corporal Afro-Brasileira. Belo Horizonte. Editora Nadyala, 2013.

\title{
"Ginga" dialectics: performances of the subaltern bodies in movement
}

\begin{abstract}
This article aims to problematize the native concept of "ginga" derived from the practice of capoeira, based on the social situation lived in the Brazilian electoral process of 2018, with the assassination of Moa do Katendê Master. This research tries to demonstrate that the "ginga" constitutes an aesthetic and symbolic device which is part of the performative repertoire of capoeira practitioners and can be understood as an artifact of navigation and social action of "capoeiristas" in the context of their subordination. This is a case study based on the monitoring of the Master's murder in the electoral context, but also on the combination of academic and political worries that concern the experiences of a researcher who is also a capoeira practitioner.
\end{abstract}

Keywords: Performance. “Ginga”. Capoeira. Hidden speeches.

\section{Dialécticas de la "ginga": performances de los cuerpos subalternos en movimiento}

\section{Resumen}

Este artículo tiene por finalidad problematizar el concepto nativo de "ginga" oriundo de la práctica del deporte intitulado "capoeira", teniendo como base la situación social vivida en el proceso electoral brasileño de 2018, con el asesinato del Mestre Moa do Katendê. Esta investigación intenta demostrar que la "ginga" es un dispositivo estético y simbólico que forma parte de la performance de los practicantes de capoeira y puede ser comprendida como artefacto de navegación y acción social de los “capoeiristas", en el contexto de subordinación. Se trata de un estudio de caso en el que se parte del estudio del asesinato del Mestre en el contexto electoral, pero también de la conjugación de las inquietudes académicas y políticas que conciernen a las vivencias de un investigador-practicante de capoeira.

Palabras clave: Performance."Ginga”. Capoeira. Discursos ocultos.

Data de recebimento do artigo: 05/11/2018

Data de aprovação do artigo: 28/03/2019 